\title{
Abrasive water jet review and parameter selection by AHP method.
}

\author{
Y.B Gaidhani ${ }^{1}$, V.S.Kalamani ${ }^{2}$ \\ ${ }^{1}$ Department of Mechanical Engineering, K.K.Wagh Polytechnic,Nasik.) \\ ${ }^{2}$ (Department of Mechanical Engineering, K.K.Wagh Polytechnic,Nasik.)
}

\begin{abstract}
An Abrasive Water Jet is one of the most recently developed non-traditional manufacturing processes. Abrasive water jet offers the potential for the development in cutting which is less sensitive to material properties, has virtually no thermal effects, and imposes minimal stresses. As it is a cold process has also important applications where heat-affected zones are to be avoided. In this work, a deep study of this newer non-conventional technique of machining i.e., abrasive water jet machining is done. In this paper more focus is on selection of various process parameters like-angle of impact, Pressure inside the pumping system, abrasive material type, Stand-off distance, focusing tube diameter, nozzle speed, abrasive mass flow rate and target material properties for getting the required output like- depth of cut and cut quality. For cutting Stainless steel (Grade 304), important task is to find out a few parameters which influence more. With the help of Analytical Hierarchy Process technique the selection of a few parameters are done which are comparatively more influencing. Weighteges are given to parameters on the basis of previous study and experience of owner of the company who is dealing with abrasive water jet technology since many years.
\end{abstract}

Keyword-AHP Technique, process parameter, Quality of cut, Weight ages.

\section{Inroduction}

Cutting of stainless steel plates without losing its metallurgical properties for the purpose of making fixtures part was the problem. Literature review provided solution and abrasive waterjet technique suited best for the given practical problem. Abrasive waterjet (AWJ) machining technology has been found to be one of the most recent developed advanced non-traditional methods used in industry for material processing with the distinct advantages of no thermal distortion, high machining versatility, high flexibility and small cutting forces. Various machining technologies of high-speed cutting by using of liquid jets can be included in this category. High speed of the out flowing stream of water containing abrasives makes it possible to machine many industrial materials such as paper, paperboard, wood, plastic, building materials, rocks and also metals and their alloys [2].Experimental study of the surface quality produced by abrasive waterjet (AWJ) on metallic materials and measurement of surface roughness/waviness was quantitatively evaluated by using the contactless optical measurement is done by the researcher [2]. The waterjet is a versatile tool and can be used in applications such as cutting, drilling, and milling, cleaning, peening, forming and coating removal. It can machine almost any material and competes with other technologies since there is minimal force, no heat damage and it is an environmentally friendly process. The drive for flexibility, speed and harder to process materials has meant that the uptake of waterjet technology in recent years has risen significantly. The process can be used with or without the addition of abrasive media and new applications are being continuously found [1].Researcher reported effect of abrasive material type on surface cut quality [4]. Abrasive waterjet cutting has been proven to be an effective technology for processing various engineering materials. Surface roughness of machined parts is one of the major machining characteristics that play an important role in determining the quality of engineering components [5].

In this paper aim is to find important process parameter which will be use for the further experimentation. Literature review provided consequences among various process parameters which affects the cutting quality and this is solved with the help of AHP technique. Three topographical components-waviness, roughness and error of form-compose a machined parts surface texture .the irregular nature of a surface texture arises from several parameters [3].

\subsection{Machining centre and cutting objects of waterjet cutting.}

Nowadays, this process is being widely used for machining of hard to machine materials like ceramics, ceramic composites, fiber-reinforced composites, and titanium alloys where conventional machining is often not technically or economically feasible. The fact that it is a cold process has important implications where heataffected zones are to be avoided. High-pressure water starts at the pump, and is delivered through special highpressure plumbing to the nozzle. At the nozzle, abrasive is (typically) introduced, and as the abrasive/water mixture exits, cutting is performed. Once the jet has exited the nozzle, the energy is dissipated into the catch 
tank, which is usually full of water and debris from previous cuts [2]. A general machine which we will actually used for the future experimentation is shown in following figure which clears the idea about machine (Name of machine: Techni Pac, Name of the company: Supernova waterjet ltd).

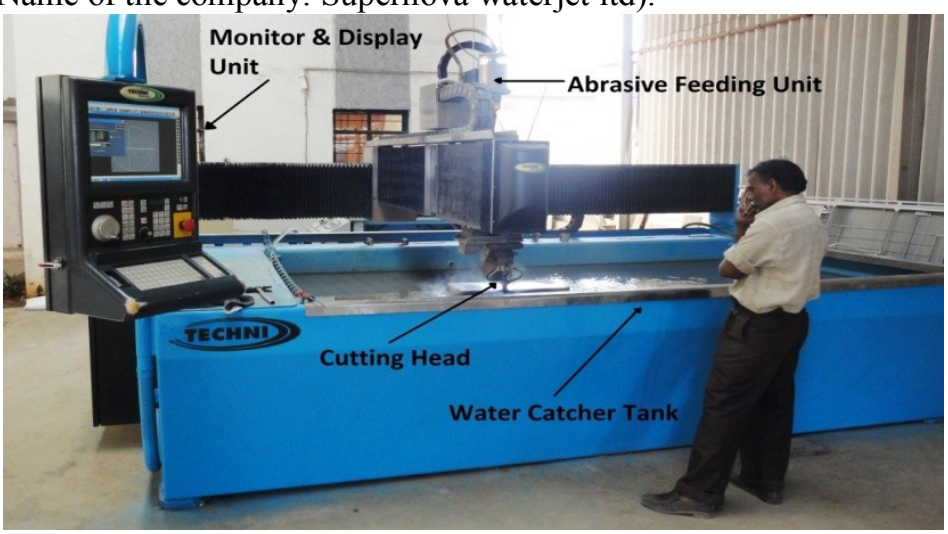

Fig: 1 Machining centre for abrasive waterjet cutting (SUPERNOVA waterjet ltd).

The waterjet is a versatile tool and can be used in applications such as cutting, drilling, milling, cleaning, peening, forming and coating removal.It can cut any types of shpe irrespective of the material live example of which are shown in figure with different material like ceramic,green marble,steel,glass.

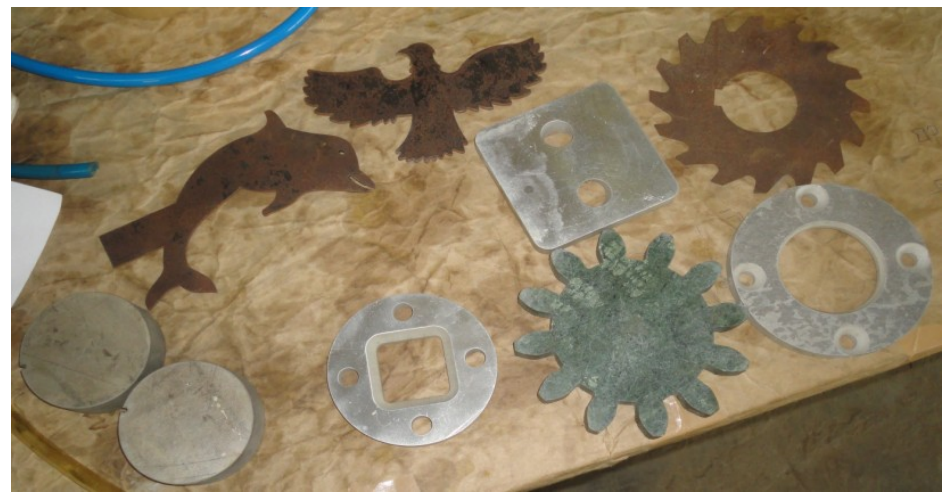

Fig: 2 Different waterjet cutting product.

\section{Objectives and Issues}

In modern era of manufacturing technology and industrialization, every manufacturing method has to ensure that it should meet the international standards and quality requirement to remain competent in this rapidly changing industrial environmental. To achieve this, it is a necessary requirement that cutting with the abrasive waterjet should provide good cutting quality with less damage to material properties .So for this necessary inputs (process parameters) should be selected correctly for the cutting of Stainless steel - Grade 304 plate . The main objective of the paper is to rate parameters (angle of impact, pressure inside the pumping system, abrasive material type, abrasive mass flow rate, standoff distance, focusing tube diameter and material properties) with respect to various criteria. Here in this paper we are presenting an easy to understand approach for solving this problem with the help of AHP technique. For this, a questionnaire based study has been adopted and views of experts from industry and academia have been taken.

\subsection{Analytical Hierarchy Process Approach.}

\section{Methodology}

One of the most popular analytical techniques for complex decision making problems is analytic hierarchy process. Saaty developed The Analytic Hierarchy Process (AHP), which decomposes a decision making problem in to a system of hierarchies of objectives, attributes and alternatives. In this study AHP is used to calculate weight ages and confirm the consistency. An AHP can have as many levels as needed to fully characterize a particular decision situation. A number of functional characteristics make AHP a useful methodology. These include the ability to handle decision situations involving subjective judgments, multiple decision makers and the ability to provide measures of consistency of preference. Designed to reflect the way people think, AHP continues to be the most highly regarded and widely used decision-making method. Thomas L. Saaty, (2008) The Analytic Hierarchy Process (AHP) is a theory of measurement through pair wise 
comparisons and relies on the judgements of experts to derive priority scales. It is these scales that measure intangibles in relative terms. The comparisons are made using a scale of absolute judgements that represents how much more; one element dominates another with respect to a given attribute.

Problem of selection of process parameters has been dealt with by using questionnaire based study. A structured questionnaire was framed and all the criteria are rated by the professional of various fields.

\subsection{Important process parameter and its selection.}

There are several parameters that affect the cutting performance of the abrasive water jet: Hydraulic parameters; water jet nozzle diameter and supply pressure, Abrasive parameters; abrasive material, abrasive size and abrasive flow rate, Mixing parameters; mixing tube dimensions and nozzle material, Cutting parameters; traverse rate, standoff distance, impingement angle and depth of cut and material to be cut. Abrasive water jet machining is a relatively new machining technique in that it makes use of the impact of abrasive material to erode the work piece material. It relies on the water to accelerate the abrasive material and deliver the abrasive to the work piece.

Following figure shows fishbone diagram showing five main factors with their sub factors which affects the depth of cut quality.

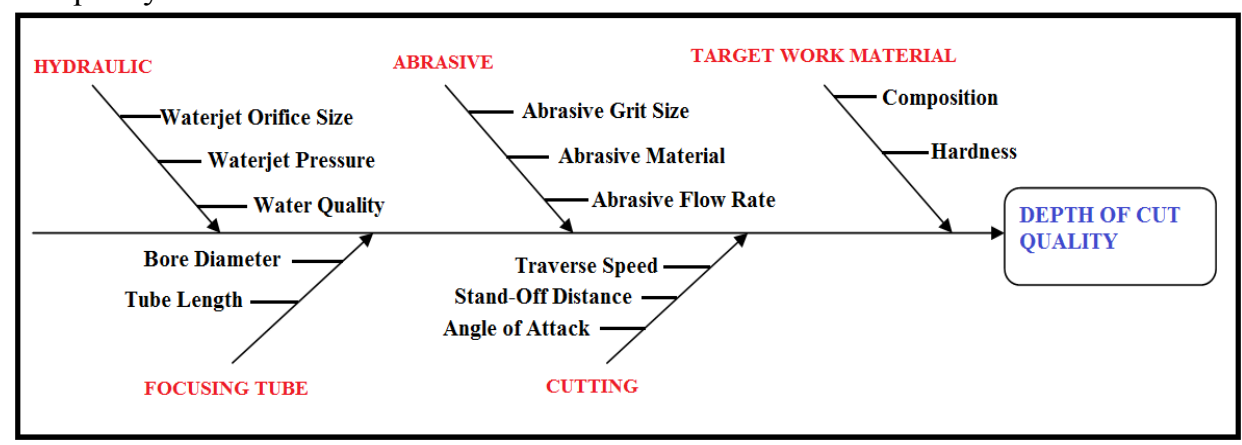

Fig 3: Process parameters influencing the AWJ cutting process.[7]

With the help of different literature review different process parameters which influences AWJ cutting were observed. Following are different performance measure generally expected from AWJ cutting with various materials

1. Depth of cut and cut quality.2.Material removal rate. 3. Kerf topography.4.Kerf geometry.5.Cutting time. For achieving above performance measure following parameters plays an important role.

1. Angle of impact. 2. Pressure inside the pumping system.3.Abrasive material type.4.Stand-off distance.5. Focusing tube diameter.6. Nozzle speed.7. Abrasive mass flow rate. 8 Target material properties.

\subsection{Implementation of AHP technique with the help of manual calculation.}

A decision is a choice made from two or more alternatives. Decision-making is the process of sufficiently reducing uncertainty and doubt about alternatives to allow a reasonable choice to be made among them. Researchers have studied different decision-making problems by using different decision-making methods such as the analytic hierarchy process (AHP), fuzzy multiple-attribute decision making model, linear and $0-1$ integer programming models, genetic algorithms (GA), etc. The Analytic Hierarchy Process (AHP) is due to Saaty (1980) and is often referred to, eponymously, as the Saaty method. The Analytic Hierarchy Process is powerful and flexible decision making process to help people set priorities and make the best decision when both qualitative and quantitative aspects of decision need to be considered .By reducing complex decision to a series of one -on-one comparison, then synthesizing the results. In current abrasive water jet cutting experiment confusion is with selection of different process parameters for conducting experiments so this technique is used.

\subsubsection{Input to AHP software}

In this paper all parameters are compared to each other on the basis of scale explain in given table with the help of satty rating scale explain in the following table. 
Table 1: The Saaty Rating Scale [6]

\begin{tabular}{|l|l|l|}
\hline $\begin{array}{l}\text { Intensity } \\
\text { of } \\
\text { importance }\end{array}$ & Definition & Explanation \\
\hline 1 & Equal importance & Two parameters contribute equally to the objective. \\
\hline 3 & Weak importance of one over another & $\begin{array}{l}\text { Experience and judgment slightly favour one parameter } \\
\text { over another. }\end{array}$ \\
\hline 5 & Essential or strong importance & $\begin{array}{l}\text { Experience and judgment strongly or essentially Favour } \\
\text { one parameter over another. }\end{array}$ \\
\hline 7 & Very strong and demonstrated & $\begin{array}{l}\text { A parameter is strongly favored over another and its } \\
\text { dominance demonstrated in practice. }\end{array}$ \\
\hline 9 & Absolute importance & $\begin{array}{l}\text { The evidence favouring one parameter over another is of } \\
\text { the highest degree possible of affirmation. }\end{array}$ \\
\hline 246 & Intermediate values between adjacent scale values & $\begin{array}{l}\text { Used to represent compromise between the } \\
\text { Preferences listed above. }\end{array}$ \\
\hline \multicolumn{2}{|c|}{ Reciprocals } & Reciprocals for inverse comparison. \\
\hline
\end{tabular}

\subsubsection{Pair wise comparisons for all factors.}

Information and the priority weights of elements obtained from a decision-maker of the company using direct questioning and a questionnaire method. With this information all comparison values are put in the following table. Analysis of the problem is done by using following steps.

Step 1: Fillng of pair wise comparison table with their intensity values.

Step 2: Preparation of Pair wise comparisons matrix.

Step 3: Prepairation of Normalized matrix.

Step 4: Calculation of lambda value, Principal Eigen value, Consistency index (CI) and Consistency ratio (CR).

Step 5: Manual calculation of AHP by using comparison matrix.

Step 6: Final output table showing weigh age for parameters i.e. output of AHP.

Table 2: Pair wise comparison.

\begin{tabular}{|c|c|c|c|c|}
\hline \multicolumn{3}{|c|}{ Element } & \multirow[t]{2}{*}{ More Important } & \multirow{2}{*}{$\begin{array}{c}\text { Intensity } \\
(1-9)\end{array}$} \\
\hline A & Comparison vs. & $\mathrm{B}$ & & \\
\hline \multirow[t]{7}{*}{ Angle of impact } & \multirow[t]{7}{*}{ Vs. } & Pressure inside the pumping system & $\mathrm{A}$ & 1 \\
\hline & & abrasive material type & $\mathrm{B}$ & 3 \\
\hline & & Stand-off distance & $\mathrm{B}$ & 5 \\
\hline & & focusing tube diameter & $\mathrm{A}$ & 1 \\
\hline & & nozzle speed & $\mathrm{B}$ & 5 \\
\hline & & abrasive mass flow rate & $\mathrm{B}$ & 6 \\
\hline & & target material properties & $\mathrm{A}$ & 1 \\
\hline \multirow{6}{*}{$\begin{array}{l}\text { Pressure inside the } \\
\text { pumping system }\end{array}$} & & abrasive material type & $\mathrm{A}$ & 1 \\
\hline & & Stand-off distance & $\mathrm{B}$ & 3 \\
\hline & & focusing tube diameter & A & 1 \\
\hline & & nozzle speed & $\mathrm{B}$ & 5 \\
\hline & & abrasive mass flow rate & $\mathrm{B}$ & 3 \\
\hline & & target material properties & $\mathrm{A}$ & 1 \\
\hline \multirow[t]{5}{*}{ Abrasive material type } & \multirow[t]{5}{*}{ Vs. } & Stand-off distance & $\mathrm{A}$ & 1 \\
\hline & & focusing tube diameter & A & 3 \\
\hline & & nozzle speed & A & 1 \\
\hline & & abrasive mass flow rate & A & 1 \\
\hline & & target material properties & A & 3 \\
\hline \multirow[t]{4}{*}{ Stand-off distance } & \multirow{4}{*}{ Vs. } & focusing tube diameter & A & 3 \\
\hline & & nozzle speed & A & 1 \\
\hline & & abrasive mass flow rate & A & 1 \\
\hline & & target material properties & A & 3 \\
\hline \multirow[t]{3}{*}{ Focusing tube diameter } & \multirow{3}{*}{ Vs. } & nozzle speed & A & 1 \\
\hline & & abrasive mass flow rate & $\mathrm{A}$ & 1 \\
\hline & & Target material properties. & A & 5 \\
\hline \multirow[t]{2}{*}{ nozzle speed } & \multirow[t]{2}{*}{ Vs. } & abrasive mass flow rate & $\mathrm{A}$ & 1 \\
\hline & & target material properties & A & 5 \\
\hline
\end{tabular}




\subsubsection{Analysis of problem is given by (AHP) software.}

After doing pair wise comparison in above table all values are automatically entered in $8 * 8$ matrixes which is shown in table given below. This analysis gives normalised principal eigenvector which is then used for the next iteration .calculation is done up to six iteration.

Table 3: Pair wise comparisons matrix.

\begin{tabular}{|c|c|c|c|c|c|c|c|c|}
\hline & $\begin{array}{l}\text { Angle } \\
\text { Of }\end{array}$ & $\begin{array}{c}\text { Water } \\
\text { Pressure }\end{array}$ & $\begin{array}{l}\text { Abrasive } \\
\text { material }\end{array}$ & $\begin{array}{l}\text { Standoff } \\
\text { distance }\end{array}$ & $\begin{array}{c}\text { Focusing } \\
\text { tube }\end{array}$ & Nozzle speed & $\begin{array}{c}\text { Abrasive } \\
\text { mass }\end{array}$ & $\begin{array}{c}\text { Target } \\
\text { material }\end{array}$ \\
\hline Angle of & 1 & 1 & $1 / 3$ & $1 / 5$ & 1 & $1 / 5$ & $1 / 6$ & 1 \\
\hline Water Pressure & 1 & 1 & 1 & $1 / 3$ & 1 & $1 / 5$ & $1 / 3$ & 1 \\
\hline Abrasive & 3 & 1 & 1 & 1 & 3 & 1 & 1 & 3 \\
\hline Standoff & 5 & 3 & 1 & 1 & 3 & 1 & 1 & 3 \\
\hline Focusing tube & 1 & 1 & $1 / 3$ & $1 / 3$ & 1 & 1 & 1 & 5 \\
\hline Nozzle speed & 5 & 5 & 1 & 1 & 1 & 1 & 1 & 5 \\
\hline Abrasive mass & 6 & 3 & 1 & 1 & 1 & 1 & 1 & 3 \\
\hline Target material & 1 & 1 & $1 / 3$ & $1 / 3$ & $1 / 5$ & $1 / 5$ & $1 / 3$ & 1 \\
\hline
\end{tabular}

3.4 AHP technique with the help of AHP software and manual calculation.

AHP software is also use for the normalisation of matrix and calculation of principal Eigen value, lambda value and consistency which is shown in following table.

Table 4: normalized matrix

\begin{tabular}{|l|l|l|l|l|l|l|l|l|}
\hline & Angle & $\begin{array}{c}\text { Water } \\
\text { Pressur }\end{array}$ & $\begin{array}{c}\text { Abrasive } \\
\text { material }\end{array}$ & $\begin{array}{c}\text { Standoff } \\
\text { distance }\end{array}$ & $\begin{array}{c}\text { Focusin } \\
\text { g tube }\end{array}$ & $\begin{array}{c}\text { Nozzle } \\
\text { speed }\end{array}$ & $\begin{array}{c}\text { Abrasiv } \\
\text { e mass }\end{array}$ & $\begin{array}{c}\text { Target } \\
\text { material }\end{array}$ \\
\hline Angle of & 0.043 & 0.062 & 0.055 & 0.038 & 0.089 & 0.035 & 0.028 & 0.045 \\
\hline Water & 0.043 & 0.062 & 0.166 & 0.064 & 0.089 & 0.035 & 0.057 & 0.045 \\
\hline Abrasive & 0.130 & 0.062 & 0.166 & 0.192 & 0.267 & 0.178 & 0.171 & 0.136 \\
\hline Standoff & 0.217 & 0.187 & 0.166 & 0.192 & 0.267 & 0.178 & 0.171 & 0.136 \\
\hline $\begin{array}{l}\text { Focusing tube } \\
\text { Nozzle speed }\end{array}$ & 0.043 & 0.062 & 0.055 & 0.064 & 0.089 & 0.178 & 0.171 & 0.227 \\
\hline Abrasive mass & 0.260 & 0.312 & 0.166 & 0.192 & 0.089 & 0.178 & 0.171 & 0.227 \\
\hline \multicolumn{1}{c|}{ Target } & 0.043 & 0.062 & 0.166 & 0.192 & 0.089 & 0.178 & 0.171 & 0.136 \\
\hline
\end{tabular}

Table 5: Lambda value.

\begin{tabular}{|c|c|c|c|c|c|c|c|c|}
\hline $\begin{array}{l}\text { Lambda } \\
\text { Value. }\end{array}$ & 1.088 & 1.223 & 0.047 & 0.979 & 1.248 & 1.021 & 1.994 & 0.079 \\
\hline principal Eigen value & \multicolumn{8}{|c|}{ Total of all above lambda value $: 8.682$} \\
\hline Consistency index $(\mathrm{CI})$ & \multicolumn{8}{|c|}{0.097} \\
\hline Consistency ratio(CR) & \multicolumn{8}{|c|}{$6.9 \%$} \\
\hline
\end{tabular}

The above matrix for depicts the outcome from the pair-wise comparison of the key factors in the example. To establish the priorities of the factors, the analysis needs to calculate the sum of all the values for each row of the matrix, and then divide each of these individual row sums by the sum of the results for all rows and priorities are calculated as follows.

Table 6: Manual calculation table.

\begin{tabular}{|l|l|l|l|l|r|}
\hline & Relative importance & Row sum & Calculation & Weight age & Rank \\
\hline Angle of impact & $1+1+1 / 3+1 / 5+1+1 / 5+1 / 6+1$ & 4.9 & $4.9 / 94.83$ & $0.0510=5 \%$ & 7 \\
\hline Water Pressure & $1+1+1+1 / 3+1+1 / 5+1 / 3+1$ & 5.86 & $5.86 / 94.83$ & $0.06186=6 \%$ & 6 \\
\hline $\begin{array}{l}\text { Abrasive } \\
\text { material type }\end{array}$ & $3+1+1+1+3+1+1+3$ & 14 & $14 / 94.83$ & $0.0147=15 \%$ & 4 \\
\hline $\begin{array}{l}\text { Standoff } \\
\text { distance }\end{array}$ & $5+3+1+1+3+1+1+3$ & 18 & $18 / 94.83$ & $0.189=19 \%$ & 2 \\
\hline $\begin{array}{l}\text { Focusing tube } \\
\text { diameter }\end{array}$ & $1+1+1 / 3+1 / 3+1+1+1+5$ & 10.66 & $10.66 / 94.83$ & $0.1124=11 \%$ & 5 \\
\hline Nozzle speed & $5+5+1+1+1+1+1+5$ & 20 & $20 / 94.83$ & $0.210=21 \%$ & 1 \\
\hline $\begin{array}{l}\text { Abrasive mass } \\
\text { flow rate }\end{array}$ & $6+3+1+1+1+1+1+3$ & 17 & $17 / 94.83$ & $0.1792=17 \%$ & 3 \\
\hline $\begin{array}{l}\text { Target material } \\
\text { properties. }\end{array}$ & $1+1+1 / 3+1 / 3+1 / 5+1 / 5+1 / 3+1$ & 4.4 & $4.4 / 94.83$ & $0.0463=5 \%$ & 8 \\
\hline
\end{tabular}


Sample calculation: for angle of impact

Weight age of angle of impact $=[\text { Row sum } / \text { sum of the results for all rows }]^{*} 100$

$$
\begin{aligned}
& =[1+1+1 / 3+1 / 5+1+1 / 5+1 / 6+1] / 94.83 \\
& =[4.9 / 94.83]^{*} 100 \\
& =0.0510 * 100
\end{aligned}
$$

Weight age $=\mathbf{5 \%}$

Similarly all calculations are done manually and put in the following table.

Table: 7 Ranking of process parameters by AHP

\begin{tabular}{|c|c|c|}
\hline Participant/Criteria & Rank & Weight ages (\%) \\
\hline Standoff distance & 1 & 19 \\
\hline Nozzle speed & 2 & 17 \\
\hline Abrasive mass flow rate & 3 & 17 \\
\hline Abrasive material type & 4 & 11 \\
\hline Focusing tube diameter & 5 & 5 \\
\hline Water Pressure & 6 & 5 \\
\hline Angle of impact & 8 & 5 \\
\hline
\end{tabular}

\section{Conclusion.}

Abrasive waterjet technology provides tremendous benefits in the manufacturing field as it is environmental friendly process .Materials which are undergone through this process has no metallurgical property change effect as there is no heat affected zones. Careful monitoring and handling high pressure pumps, high pressure water line and recycling of used water provides limitation to this technology. For cutting Stainless Steel (Grade 304) important task was to select the few parameters for the experimentation purpose which is successfully done with the help of AHP .Standoff distance with $19 \%$, nozzle feed rate with $18 \%$, abrasive flow rate and abrasive material type with $17 \%$ weightege are the comparatively important parameters which are used for further experimentation.

\section{Acknowledgements}

I heartily thank to Dr. P.S.Kalos and Dr. P.J.Pawar for their regular guidance. I also express my heartfelt gratitude to Mr. Laggad sir owner of Supernova Waterjet ltd. Nasik for allowing me to survey and study actual waterjet machining centre.I am also thankful to Principal of K.K. Wagh polytechnic Prof.P.T.Kadve for his regular encouragement.

Journal papers:

\section{References}

[1] Janet Folkes, Waterjet - an innovative tool for manufacturing. Journal of Materials Processing Technology 209 (2009) 6181-6189.

[2] Jan Valic, Experimental analysis of irregularities of metallic surfaces generated by abrasive waterjet, International Journal of Machine Tools \& Manufacture 47 (2007) 1786-1790.

[3] R.Covasevic, Surface texture in Abrasive water jet cutting.

[4] A.A. Khan, M.M. Haque, Performance of different abrasive materials during abrasive water jet machining of glass. Journal of Materials Processing Technology 191 (2007) 404-407

[5] M. Chithirai Pon Selvan, and Dr. N. Mohana Sundara Raju, "Analysis of surface roughness in abrasive waterjet cutting of cast iron". International Journal of Science, Environment and Technology, Vol. 1, No 3, 2012, 174-182

[6] Sanjay Kumar, Neeraj Parashar, Abid Haleem, Analytical Hierarchy Process Applied to Vendor Selection Problem: Small Scale, Medium Scale and Large Scale Industries ,Business Intelligence Journal - August, 2009 Vol. 2 No. 2

[7] Ahmet Hasc,alık, "A study on surface roughness in abrasive waterjet machining process using artificial neural networks and regression analysis method". Journal of materials processing technology 202 (2008) 574-582. 